\title{
X-ray diffraction method application to assess the energy losses on explosive-rock contact under various blasting
}

\author{
Ihor Kratkovskyi ${ }^{1,}{ }^{*}$, Ernest Yefremov $^{1}$, Kostyantyn Ishchenko ${ }^{1}$, and Sergo Khomeriki ${ }^{2}$ \\ ${ }^{1}$ Institute of Geotechnical Mechanics named by N. Poljakov of National Academy of Sciences of \\ Ukraine, 49005, Dnipro, Simferopolska Str., 2a, Ukraine \\ ${ }^{2}$ Mining Institute named by G. Tsulukidze, 0186, Tbilisi, Mindeli Str., 7, Georgia
}

\begin{abstract}
Annotation. The dissipative energy losses of the explosion on the explosive-rock contact are usually evaluated with comparative analysis of the particle size distribution of finely dispersed fractions (0-100 microns). The more tiny particles contained in the destruction products, the higher there is a level of energy loss during the explosion. Fine dust granulometric characteristics are determined by processing the mass measurements data of the individual smallest particles sizes when decoding microphotographs obtained by a microscope. However due to the chromatic aberrations due the wave nature of light and the optical systems imperfection, it is not possible to reliably estimate the mass and granulometric characteristics particles of micron size. X-ray diffraction method for studying ultrafine rock fracture products makes it possible to estimate the dissipative energy losses on explosive-rock contact based on the reflected X-ray beam total intensity in diffractograms. In order to establish the effectiveness of methods for reducing the level of dissipative energy losses of an explosion, $\mathrm{X}$-ray diffraction patterns of finely dispersed fracture products of rock samples under various conditions of dynamic loading are analyzed (using different charge designs, attenuating the rocks by the action of a surfactant, and the force action of a different gradient stress field).
\end{abstract}

\section{Introduction}

The formation of the smallest particles less than $1 \mu \mathrm{m}$ in size in crystalline rocks of various origins (igneous, sedimentary and metamorphic is due to the peculiarities of the explosion mechanism action in polymineral media.

Thus, the character of destruction polymineral medium primarily is influenced by two factors. The first factor is the branching phenomenon of a growing microcrack at the wave stage of the explosion, when the crack growth rate exceeds a value equal to 0.6 of the shear wave velocity in the rock being destroyed [1]. The second factor is the presence in the rockforming mineral grains of structural defects in the form of intragranular and intergranular microcracks, cleavage planes of minerals, intergranular contacts and various kinds of inclusions (tiny gas and liquid bubbles) along which newly formed fracture surfaces

\footnotetext{
${ }^{*}$ Corresponding author: kratkovsky@i.ua
} 
develop. For example, according to [2], in $1 \mathrm{~cm}^{3}$ of quartz - one of the main rock-forming minerals of crystalline rocks of various genesis - up to $2 \times 10^{9}$ various inclusions (structural defects) can be present. Thus, in the explosive destruction of rock, part of the energy of ordered processes (controlled crushing) is converted to the energy of non-ordered processes (the formation of ultra-small particles of micron and submicron sizes). As a result, the socalled dissipation of explosion energy occurs, ultimately leading to a decrease in the explosion efficiency [3]. In the nature of explosive crushing of rock mass, this is reflected in an increase in the volume of oversized and dusty fractions. Crushing oversized of rock pieces leads to additional material costs. Fine particles of rock destroyed by an explosion for some types of rocks used, for example, in the production of building materials, are, in fact, irreplaceable losses of minerals resources [4]. The creation of effective methods to reduce the dissipative energy losses during the explosion on the contact of the explosive with the rock being destroyed is currently relevant from the point of view of resource and energy conservation.

The purpose of the work is evaluations the effectiveness of ways to reduce the level of dissipative energy losses of an explosion by an X-ray diffraction method for studying finely dispersed particles formed on a contact with a rock being destroyed.

\section{Experimental methods for studying dissipative explosion energy losses during rock destruction}

The level of dissipative losses of explosion energy associated with processes occurring on the explosive-rock contact is evaluated by a comparative analysis of the particle size characteristics and mineralogical composition of finely divided fractions $(0-100 \mu \mathrm{m})$. The smaller the average particle diameter and the larger their content in the fraction $0-100 \mu \mathrm{m}$, the higher are the level of dissipative loss of explosion energy. The particle size characteristics of fine dust $(0-100 \mu \mathrm{m})$ are determined by processing mass data of the diameters of individual particles by deciphering microphotographs of the smallest particles obtained using a petrographical microscope equipped with a digital camera with a resolution of at least 5 megapixels.

It should be noted that this method of evaluating the dissipative energy losses of an explosion on the "explosive-rock" contact is associated with a large investment of time and money in preparing samples for microscopic studies. The very research of fine particles under a microscope can only be performed by an experienced petrographer. The main negative aspect of the light-optical method for studying finely dispersed mineral particles is as follows.

Despite the fact that modern petrographical polarization microscopes can provide a maximum magnification of about $3375 \times$ when using a $90 \times$ immersion lens and a $25 \times$ eyepiece, chromatic and spherical aberrations (due to the wave nature of light and imperfect optical systems) do not allow on optical constants to diagnose the mineral composition and to lead adequate measurements of particles whose size is less than 1 micron. In addition, at high magnifications (starting from $2000 \times$ and higher), under the microscope, ultra-small particles of $1 \mu \mathrm{m}$ or less in size can be confused with surface defects of the glass slide, on which the test sample of finely dispersed fracture fragments is usually placed. In this regard, the light-optical method for studying the particle size distribution of the smallest (dusty) destruction products is limited in its capabilities and does not allow reliable estimation of the volume of ultrafine particles in the destruction products of polymineral rock. The number of fine particles of micron and submicron sizes $(1-5 \mu \mathrm{m})$ in a fraction of 0 -100 microns often exceeds $90 \%$.

Currently there are no reliable methods for determining a mass fraction of fines micron and submicron size in laboratory samples, though possible on a qualitative level (more or 
less) to identify their presence in the products of destruction polymineral rocks by X-ray analysis [5].

The method we developed for estimating the level of dissipative losses of explosion energy on the explosive - rock contact includes screening of explosive destruction products on laboratory sieves to isolate the smallest particles (fraction $0-100 \mu \mathrm{m}$ ), sequential reduction of the sample by quarting to a mass of 1-2 g, investigation of the finely dispersed fraction on an X-ray diffractometer, followed by interpretation of the diffraction patterns obtained by reflecting the X-ray beam from ultrafine fragments of explosive rock destruction. This method allows, in principle, a comparative analysis of the smallest fracture products (fraction $0-100 \mu \mathrm{m}$ ) of polymineral rocks formed under various conditions of explosive loading.

The essence of the method for estimating dissipative energy losses of an explosion on the explosive-rock contact is as follows.

The X-ray diffraction or diffraction method is, as is known [5], one of the excellent methods for the diagnosis of crystals, for which it is mainly used. However, due to the limited accuracy of X-ray equipment, it is often difficult to determine whether a solid is a substance with very small crystals or glass with an amorphous structure. In the study by this method the smallest crystalline particles, such as particles of quartz dust, a so-called zone "amorphization" stands out clearly on the X-ray spectrum. The more ultrafine particles present in the analyzed sample, the higher the intensity of the X-ray beam (measured in pulses per second) reflected from the particles. In X-ray diffraction patterns, the "amorphization" zone associated with ultrafine particles of rock dust on the abscissa is limited by the angle $2 \theta$ within $5-20^{\circ}$.

In estimating the relative volume of the smallest particles we use diffractograms recorded on X-ray unit (diffractometer) by standard methods, when applied as an X-ray beam tube with monochromatic $\mathrm{Cu}-\mathrm{K}_{\alpha}$ radiation. Samples for $\mathrm{X}$-ray studies are fine fraction polymineral rocks of various genesis, destroyed dynamic loadings of high intensity (explosion impact). Since the X-ray diffraction patterns of the analyzed samples are usually automatically recorded in the format of standard spreadsheets, the total intensity of the reflected X-ray beam is easily determined by using the summation function also standard for these programs.

This technique is universal and can be used to study finely dispersed crushing products of polymineral or monomineral rocks of any genesis destroyed by dynamic loads of various intensities (explosion, free impact, high speed impact, etc.). When studying the smallest products of rock destruction by the X-ray diffraction method, there is no need to prepare special mineralographic preparations used in the study of the smallest mineral particles by light-optical microscopy [6].

\section{Results and discussion}

\subsection{Assessment of the level of dissipative energy losses explosion on contact with the rock explosives using X-ray diffraction patterns at various conditions of dynamic loading rocks}

The effectiveness of various methods for the effect of dissipative energy losses on the explosive-rock contact under dynamic loading conditions is tested under the following conditions of dynamic loading of rocks. Firstly, it is an estimate of the energy losses of an explosion with a deliberate change in the properties of a destructible medium (saturation of a rock with surface-active substances to reduce the strength of rocks of various origins). Secondly, it is the use of various designs of borehole charges (inert gap between rock and 
explosives. Thirdly, this is the use of variable diameter charges to create a diverse gradient of destructive loads. Figure 1 shows the X-ray diffraction pattern of the products of the destruction of a disco-shaped sample of limestone (diameter $59 \mathrm{~mm}$, height $10 \mathrm{~mm}$ ) destroyed by explosion of a detonating cord ( $9 \mathrm{~g}$ of explosive per meter) $1 \mathrm{~cm}$ long [7], and in Table. 1 is results of decoding of this diffractograms.

The relative volume of ultra-small particles, the size of which is less than $1 \mu \mathrm{m}$, is estimated from the total intensity of the reflected X-ray beam in the range of angle $2 \theta$ within $5-20^{\circ}$. (the region of maximum diffuseness of scattering of the reflected X-ray beam).

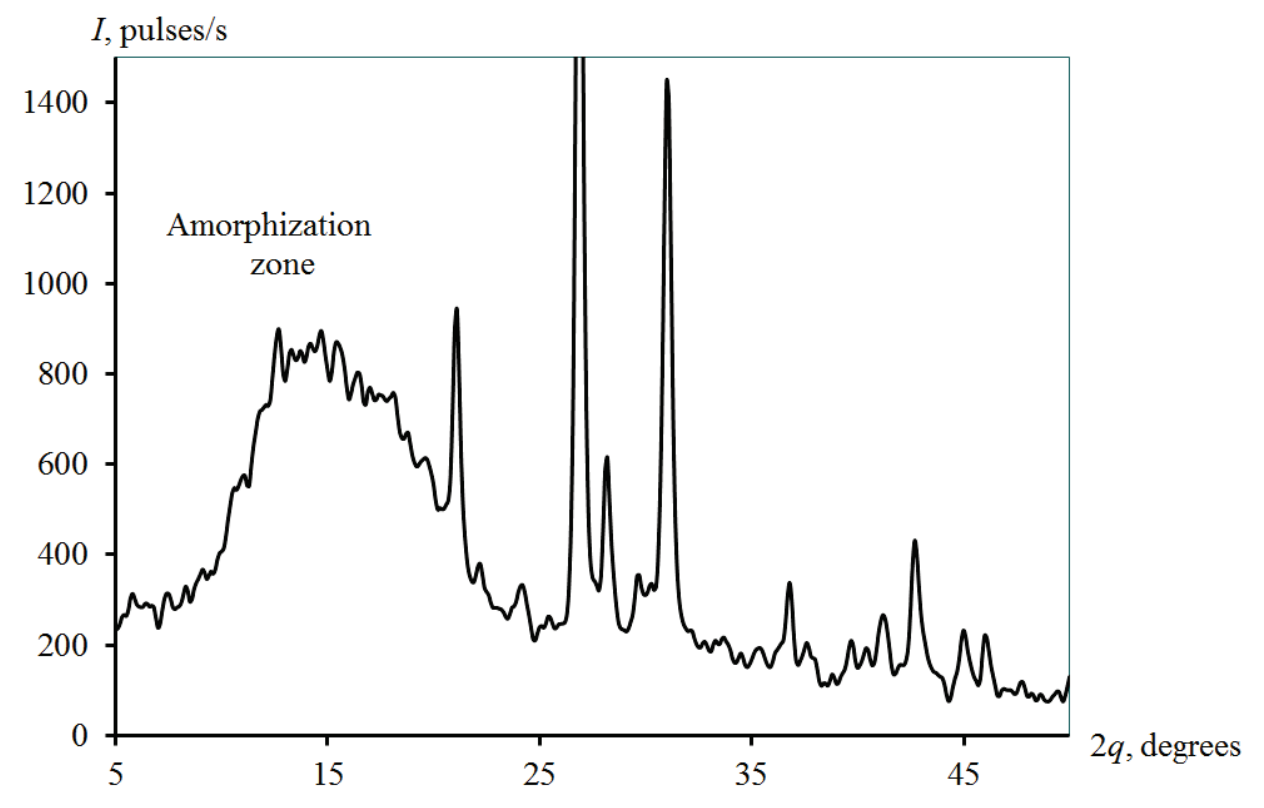

Fig. 1. X-ray diffraction pattern of ultrafine particles of limestone destroyed by a detonating cord. The shaded area is the "amorphization" zone.

Table 1. Results of X-ray diffraction analysis of limestone samples (dry and saturated with water) destroyed by pieces of detonating cord $1 \mathrm{~cm}$ long.

\begin{tabular}{|l|c|c|}
\hline $\begin{array}{c}\text { Rock type and place of } \\
\text { sampling }\end{array}$ & $\begin{array}{c}\text { Exposure conditions } \\
\text { (dry, water-saturated })\end{array}$ & $\begin{array}{c}\text { The total intensity (averaged } \\
\text { values) of the reflected X-ray } \\
\text { beam in the zone of } \\
\text { "amorphization" } \\
\left(2 \theta \text { within } 5-20^{\circ}\right), \mathrm{imp} / \mathrm{s}\end{array}$ \\
\hline $\begin{array}{l}\text { Fine-grained limestones } \\
\text { (Ukraine, Dokuchaevsk, } \\
\text { Central Quarry) }\end{array}$ & $\begin{array}{c}\text { Dry samples } \\
\text { Water saturated }\end{array}$ & 23378 \\
\cline { 2 - 3 } & within 24 hours
\end{tabular}

Studies have found that for dry limestone samples destroyed by an explosion, the average values of the total intensity of the reflected X-ray beam in the "amorphization" zone $\left(2 \theta\right.$ within $\left.5-20^{\circ}\right)$ are almost 2 times greater than for water-saturated rocks. This indicates that after saturation of the limestone with water - a kind of surface-active substance (surfactant) - the volume of the smallest particles in the products of the explosive destruction of the analyzed rock also almost halved. 


\subsection{The effect of surfactants on the dissipative loss of explosion energy in the zone of contact between explosives and rock}

A surfactant is destroyed on a rock, its contact strength decreases, as a result of which, under dynamic action (explosion, impact), newly formed fracture surfaces (microcracks) develop mainly along the contact line of the grains of rock-forming minerals. For this reason, finely dispersed fragments of the destroyed rock are represented by relatively large particles that scatter the X-ray beam to a lesser extent [8].

In order to study the effect of surfactants on the output of ultrafine particles (less than 1-2 $\mu \mathrm{m}$ ) during rock destruction by high-intensity dynamic loads, we analyzed X-ray diffraction patterns of impact products of pink granite impact (fraction 0-100 $\mu \mathrm{m}$ ), weakened by $10 \%$ solution of soda ash $\left(\mathrm{Na}_{2} \mathrm{CO}_{3}\right)$ [9].

The results of X-ray studies are given in Table. 2.

Table 2. The intensity of the total reflected X-ray beam in the "amorphization" zone (fraction 0 $100 \mu \mathrm{m}$ ) with the destruction of pink granite samples (cubes with a $40 \mathrm{~mm}$ edge, "Sivach" deposit,

Cherkassy region) with a free kick (pile driver) and the effect of surfactants.

\begin{tabular}{|c|c|c|}
\hline $\begin{array}{c}\text { Sample } \\
\text { number }\end{array}$ & $\begin{array}{c}\text { Type of surfactant and exposure } \\
\text { time }\end{array}$ & $\begin{array}{c}\text { The intensity of the total reflected } \\
\text { X-ray beam in the zone of } \\
\text { "amorphization" }\left(2 \theta \text { within } 5-20^{\circ},\right. \\
\text { fraction } 0-100 \mu \mathrm{m}), \text { impulse/s }\end{array}$ \\
\hline 29 & $\begin{array}{c}\text { No surfactant exposure } \\
\text { (dry sample) }\end{array}$ & 2995 \\
\hline 2 & $\begin{array}{c}\text { Exposure sample in ten percent } \\
\mathrm{Na}_{2} \mathrm{CO}_{3} \text { solution for } 24 \text { hours }\end{array}$ & 2019 \\
\hline
\end{tabular}

The data given in Table 2, indicate that for a finely dispersed fraction of samples destroyed by impact of polymineral rock (granite), weakened by the action of a $10 \%$ solution of soda ash $\left(\mathrm{Na}_{2} \mathrm{CO}_{3}\right)$, the intensity of the total reflected X-ray beam in the amorphization zone is almost 1.5 times lower than for a finely divided fraction of the same dry sample, but not subject to the action of surfactants. Accordingly, the level of dissipative losses of impact energy spent on the formation of ultrafine particles of destructible rock is reduced by a factor of 1.5 .

Although the treatment of surfactants destroyed by dynamic loads of polymineral rocks gives a good effect in terms of reducing the level of dissipative losses associated with the formation of the smallest particles, one should not expect a very high efficiency of this method in an industrial condition. This is due, first of all, to great technological difficulties in the formation of borehole charges with surfactants, as well as insufficient knowledge of their impact on the environment $[10,11]$. In our opinion, the way to reduce the level of dissipative losses due to the processing of destructible surfactant rocks has more prospects for the development of energy-saving methods of softening the rock mass (where shock loads are used) in the process of mineral processing.

\subsection{Effect explosives area contact with the rock to blast the dissipative energy loss}

The reduction of the area of contact between the explosive and the rock (as well as the complete elimination of such contact) can be realized due to an inert radial gap (air, water) along the entire length of the charge column or part thereof) between the explosive and the surface of the charge cavity (blasthole, hole).

The influence of the air gap on the level of dissipative losses of explosion energy associated with the formation of particles of submicron size was studied by us on X-ray 
diffraction patterns obtained in the study of finely dispersed fractions of the products of the destruction of pink granite from the Sivach deposit (Cherkassy region) by the explosion of boreholes of powdered ammonite (diameter $42 \mathrm{~mm}$, the length of the column of explosives $0.6-0.8 \mathrm{~m}$, charge mass $0.860 \mathrm{~kg}$ ). Finely dispersed fractions of $0-100 \mu \mathrm{m}$ of granite destruction products formed in the near explosion zone, continuous charge and charges with a two- and three-millimeter air annular gap between the explosive and the surface of the hole were studied.

The results of determining the level of dissipative losses are given in Table 3.

Table 3. The intensity of the total reflected X-ray beam in the "amorphization" zone during the blast destruction of granites ("Sivach" deposit, Cherkassy region) with Ammonite powder No.6 (continuous charge, diameter $42 \mathrm{~mm}$ ).

\begin{tabular}{|c|c|c|}
\hline $\begin{array}{c}\text { Sample } \\
\text { number }\end{array}$ & Charge design & $\begin{array}{c}\text { The intensity of the total reflected } \\
\text { X-ray beam in the zone of } \\
\text { "amorphization" }(2 \theta \text { within 5-20 } \\
\text { fraction } 0-100 \mu \mathrm{m}), \text { impulse/s }\end{array}$ \\
\hline \multicolumn{3}{|c|}{ Pink microcline granites (orthogranites) } \\
\hline 29 & Solid charge & 5689 \\
\hline 2 & Air ring-gap 2 mm & 1087 \\
\hline 3 & Air ring-gap 3 mm & 6356 \\
\hline 32 & Gray albite granites (alaskites) \\
\hline 30 & Solid charge & 1527 \\
\hline 4 & Air ring-gap 2 mm & 1330 \\
\hline
\end{tabular}

As can be seen from Table 3, the air gap provides a significant reduction in dissipative losses (4-6 times) associated with the formation of fine particles in the contact zone "explosive-rock", with an increase in the gap between the explosive and the rock from 2 to $3 \mathrm{~mm}$ slightly affects the volume of the smallest particles in the near blast zone. As a result of analyzing X-ray diffraction patterns, it was also established that the intensity of the total reflected X-ray beam in the "amorphization" zone (impulses/s) for gray albite granites is $10.5 \%$ more than the intensity of the reflected X-ray beam for pink microcline granites.

This is because the density of structural defects (microjoints) in quartz grains of pink granites is higher than in quartz of gray granites.

For this reason, when a stress wave is applied to a destructible medium in gray granites, it is likely that the process of cracks branching at the wave stage of the explosion will be more developed.

At the same time, newly formed by the explosion of the surface of the fracture in quartz pink granites with its growth inherit natural microjoints (intra- and intergranular).

Thus, it can be stated that in polymineral media with a lower density of structural defects (in this case, in gray albite granites) dissipative energy losses of the explosion are higher than in polymineral media with a higher structural defects density.

An inert air (water) gap between explosives and the surface of explosive boreholes in industrial conditions is usually formed with the help of a polyethylene-waterproofing sheath, the diameter of which is smaller than the diameter of the borehole [12]. Inert air (water) ring-gap charges are effective when used in open pit mining, when strong rocks (granites, syenites, quartzites, sandstones, limestones, dolomites, etc.) that are destroyed by explosion energy are used as raw materials for the production of building materials (crushed stone) or fluxes for the metallurgical industry. The resulting fine fractions are irreparable loss of mineral.

A significant drawback of charges with inert ring-gaps, despite their unconditional efficiency while reducing dissipative energy losses of the explosion, consumed for over 
grinding, is the impossibility of creating gaps of constant width. This is due to the elasticity of the polyethylene waterproofing shell, which due to the action of gravitational forces in the charging cavity takes an $S$-shape. This leads to partial contact of the explosive with rock in the zones of shell bending, as well as an increase in the specific consumption of explosives by increasing the length of the charge column of this form.

\subsection{Influence of a multi-gradient stress field on dissipative explosion energy losses}

A multi-gradient stress field is created by charges of variable diameter along the height of the ledge. The explosive is then placed in polyethylene shells, in which sections with a smaller diameter with a certain interval alternate with sections in which the diameter of the shell is equal to the diameter of the borehole. The charge of this design with partial contact of the explosive with the rock (in extended areas) provides a constant annular gap in the narrowing zones and, in addition, creates a multi-gradient loading of the destructible rock on the junction of the narrowed and expanded diameters. In such a multi-gradient field of stresses, shear stresses prevail. Since the dynamic shear strength of the rocks is approximately 5 times less than their dynamic compressive strength, the energy outlays of destroying the rock mass on the junction of the narrowed and expanded sections of the charge are significantly reduced. As a result, the crushing uniformity is improved, and in areas of a narrowed charge diameter, the dissipative losses of explosion energy spent on the regrinding of the destructible medium (polymineral rock) are reduced.

In order to determine the level of explosion energy dissipative losses due to the ultrafine particles formation on the explosive-rock contact under various conditions of multi-gradient loading, the smallest fractions were isolated by sieving the crushing products of sandcement models on laboratory sieves with a mesh size of 0-50 $\mu \mathrm{m}$.

The experiments were carried out on sand-cement models in the form of a parallelepiped with dimensions $200 \times 300 \times 200 \mathrm{~mm}$, destroyed by charges of variable cross section along its length. Multi-gradient loading of parallepipedal sand-cement models was created by simultaneously blasting two charges of variable cross section, one of which had one narrowed part with a length of $28 \mathrm{~mm}$ and a diameter of $12 \mathrm{~mm}$, and the other had two narrowed parts with a length of $14 \mathrm{~mm}$ and a length of $12 \mathrm{~mm}$. Two schemes of the impact of individual parts of the charges in the models were tested: the opposite arrangement - the expanded and narrowed sections of adjacent explosive charges are opposite each other; staggered arrangement - extended sections of adjacent charges are opposite the narrowed sections. Models were destroyed charges Ammonite No.6 (total explosive weight is $17.32 \mathrm{~g}$, specific consumption $\left.-1.43 \mathrm{~g} / \mathrm{m}^{3}[13]\right)$.

The dissipative energy losses of the explosion under multi-gradient loading of the sandcement models were determined by studying the fine fraction of the destruction products $(0-100 \mu \mathrm{m})$ with the X-ray diffraction method.

In particular, the total value of the reflected X-ray radiation (imp/s) was determined on the diffractograms recorded on the X-ray diffractometer in the form of spreadsheets. The research results are given in Table. 4.

From the Table 4 it follows that when the charges of variable diameter are staggered in the sand-cement model, the total value of the reflected X-ray beam (imp/s) decreases by about $11 \%$. Accordingly, the level of dissipative losses of explosion energy decreases by the same amount, i.e. energy spent on the formation of ultrafine (less than $5-10 \mu \mathrm{m}$ ) particles.

The decrease in dissipative losses with a staggered arrangement of explosive charges of variable diameter, in our opinion, is associated with an increase in the role of shear stresses in a multi-gradient stress field generated by two elongated explosive charges. The dynamic 
strength of solid media under the action of destructive shear stresses, as is known, is 5 times less than under the action of compressive stresses.

Table 4. Results of X-ray diffraction establishment of dissipative energy losses explosion during the formation of ultrafine particles (fraction 0-100 $\mu \mathrm{m}$ ) on the explosive-rock contact under various conditions of multi-gradient loading.

\begin{tabular}{|c|c|}
\hline $\begin{array}{c}\text { Placement of elongated charges of variable } \\
\text { diameter along their length } \\
\text { in a sand-cement model }\end{array}$ & $\begin{array}{c}\text { The total value of the reflected X-ray } \\
\text { beam in the zone of "amorphization" } \\
\left(2 \theta \text { within } 5-20^{\circ}\right), \text { imp/s }\end{array}$ \\
\hline $\begin{array}{c}\text { Opposite (extended and narrowed sections of } \\
\text { the charge are located opposite each other) }\end{array}$ & 7300 \\
\hline $\begin{array}{c}\text { Staggered (extended sections of the charge } \\
\text { are located opposite the narrowed sections) }\end{array}$ & 6500 \\
\hline
\end{tabular}

The staggered arrangement of elongated cylindrical charges of an explosive substance of variable diameter provides not only more uniform crushing of the destructible medium (rock), but also more efficient from the point of view of dissipative losses of explosion energy associated with the formation of ultrafine particles.

Thus, the diverse loading of rocks generated by elongated cylindrical charges of variable diameter along the height of the ledge can be recommended for widespread use in quarries for the extraction of building materials, where a decrease in dissipative losses of explosion energy is directly related to undesirable crushing of destructible rocks, which, in fact, irreplaceable, loss of mineral.

\section{Conclusions}

1. It has been experimentally established that the main dissipative energy losses of the explosion at the contact "explosive-polymineral rock" are associated with the formation of ultra-small particles whose size is less than 1 micron. The larger the volume of ultra-small fragments of the destroyed rock, the higher the level of dissipative loss of explosion energy.

2 . The reduction of dissipative losses of explosion energy associated with the regrinding of destructible rock can be achieved in the following ways: use for crushing rocks with explosives with low energy characteristics; application to reduce the contact strength of rocks of surfactants with an alkaline reaction; using to reduce the contact area of the explosive with the rock charges with ring gaps; a change in the nature of loading of the destructible mass due to a different-gradient stress field, which is generated by charges of a variable cross section over a column of cylindrical charge.

3. Elongated cylindrical charges of variable cross-section along their length are most effective for reducing dissipative losses of explosion energy when they are used in quarries for the extraction of building and flux raw materials.

\section{References}

1. Petch, N. (1973). Metallographic aspects of destruction. Razrushenie. Moskva: Mir, 1, $375-420$

2. Roedder, E. Fluid inclusion evidence for immiscibility in magmatic differentiation. Geochim. Cosmochim. Acta, 56 (1992)

3. Yefremov, E.I. et al. (2010). Sposob upravleniya razmerami zony pereizmelcheniya tverdykh sred pri ikh vzryvnom razrushenii. Suchasni resursoenerhozberigaiuchi tekhnolohii girnychoho vyrobnytsva. Kremenchuk: KDPU, 1, 7-10

4. Yefremov, E.I. et al. (1984). Mekhanica vzryvnogo razrusheniya porod razlichnoy 
struktury. K.: Naukova dumka

5. Tomson, R., Seitz, F. (1973) The structure of solids. Razrushenie. Moskva: Mir, 1, 15111

6. Voloshin, O.I. et al. (2017). Metodyka vyznachennya vmistu dioksydu kremniiu v probi vuhilnoho pylu. Svidotstvo pro reiestratsiiu avtorskoho prava na tvir No 73060 vid 24.07.2017 r. - Zareiestrovano v Minekonomrozvytku i torhivli Ukrainy

7. Yefremov, E.I. et al. (2001). Eksperimentalnye issledovaniya vliyaniya skorosti vzryvnogo nagruzheniya na vykhod pylevidnykh fraktsii pry razryshenii gornykh porod. Geotekhnicheskaya mekhanika, 26, 8-12

8. Yefremov, E.I. et al. (2012). Vliyanie dinamicheskikh nagruzok na izmenenie struktury porod razlichnogo genezisa. Naukovyi visnyk $N H U, 6,126-130$

9. Yefremov, E.I. et al. (2013). Vliyanie poverkhnostno-aktivnykh veshchestv na kharakter razrusheniya polimineralnykh porod. Rozrobka rodovyshch, 2014, D.: TOV "LizunovPres", 373-379

10. Zhilin, A.S. (2004) Study of the effect of surfactants on the effectiveness of explosive destruction of rocks. Proektirovanie, stroitelstvo $i$ ekspluatatsiia kompleksov podzemnykh sooruzhenii. Tr. Mezhdunarodnoi konf. Yekaterinburg, Mai 18-20, 2004. Yekaterinburg: Izdatelstvo UGGGA, 259-262

11. Norov, Yu.D. et al. (2010). Development of downholes charge design using surfactants. Moscow: GIAB, 4, 143-144

12. Yefremov, E.I. et al. (2012). Vliyanie konstruktsii skvazhinnogo zariada VV na izmenenie uslovii peredachi energii vzryva razrushaemoi gornoi porode. Teoriya $i$ poraktika vzryvnogo dela: MVK po vzryvnomu delu pri AGN, 392

13. Yefremov, E.I. et al. (2018). Povyshenie effektivnosti razrusheniya gornykh porod pri vzryve udlinennykh zariadov peremennogo diametra / Informatsionnyi biullenen USIV, 2 (34), 14-18 